\title{
A Case Report of Retroperitoneal Seminoma and Literature Review
}

\author{
Chiumento Costanza ${ }^{1 *}$, Fiorentino Alba ${ }^{1}$, Tartarone Alfredo ${ }^{2}$, Lapadula Loredana ${ }^{1}$, Caivano Rocchina ${ }^{1}$, Cozzolino Mariella ${ }^{1}$ and Vincenzo \\ Fusco'
}

${ }^{1}$ Department of Radiation Oncology, I. R. C. C. S. - C. R. O. B. Padre Pio Street 1, 85028 Rionero in Vulture (Pz), Italy

${ }^{2}$ Department of Medical Oncology, I. R. C. C. S. -C. R. O. B. . Padre Pio Street 1, 85028 Rionero in Vulture (Pz), Italy

\begin{abstract}
Aims and background: Extra-gonadal germ cell tumours (EGCT) are rare tumors, which usually occur in the mediastinum or retroperitoneum; in particular, primary retroperitoneal seminomas account for approximately $2 \%$ of all seminomas. We report the case of a 34-year-old male with a locally advanced retroperitonal seminoma.

Methods: The patient underwent debulking surgery followed by cisplatin-based chemotherapy and radiotherapy. Results: No evidence of recurrence was detected during a 30 months follow-up. Although retroperitoneal seminoma is rare, this entity should be considered in the differential diagnosis of a male patient presenting with a mass in the retroperitoneum.

Conclusions: Our case, according to data reported in literature, confirms the curability of retroperitoneal seminoma even in presence of bulky disease, and it represents an example of revised treatment procedure due to patient's particular condition.
\end{abstract}

Keywords: Retroperitoneal seminoma; Testicular involvement; Radiotherapy

\section{Introduction}

Germ cells tumours in men usually arise from testes, only 1-2\% originating from others locations [1].

The extra-gonadal germ cell tumours (EGCT) are rare, accounting for $0.15-0.2 \%$ of all malignancies and representing approximately $5 \%$ of all germ cells tumour (GCTs) [2].

EGCT mostly affect young men and develop from germ cells precursors that become arrested during embryological migration and colonize ectopic sites. The anatomic distribution of EGCT is varied and includes the mediastinum, sacrococcygeal region, neck, retroperitoneum and other rare sites. However, retro-peritoneum represents the second most common extra-gonadal site after mediastinum.

These tumours are predominantly non-seminomatous in histology, occur frequently in patient with Klinefelter's syndrome and are frequently associated with the development of haematological malignancies $[3,4]$.

EGCT produce a wide variety of symptoms and may reach large volumes if they arise in silent areas. In this report, we present a case of retroperitoneal seminoma.

\section{Case Report}

A 34-year-old Caucasian male, presented to the emergency department with left upper abdominal pain, nausea, fatigue and abdominal distension. The patient has a genetic malformation dysmorphic syndrome consisting in ptosis, diastasis of the abdomen rectum muscles, hip dysplasia and undescended right testis. Physical examination of left testis was normal. Tumoral markers ( $\beta$ - HCG and alpha feto protein) and LDH levels were within normal limits. Abdominal ultrasound showed a $8 \times 5 \mathrm{~cm}$ left retroperitoneal mass, extending to left kidney without hydronephrosis.

A testicular ultrasound evidenced a small left testicle size with multiple hypoechoic nodules and right undescended testicle.

A subsequent CT scan confirmed the presence of a retroperitoneal mass suggestive of a primary tumour (Figure 1).
Then the patient underwent a CT-guided biopsy, that permitted a diagnosis of classical seminoma with immunohistochemical positive reaction of neoplastic cells to placental alkaline phosphathase (PLAP) (Figure 2).

On June 2010, due to the worsening of the clinical condition, the patient underwent exstensive resection of the retroperitoneal mass plus lymphadenectomy, left nephrectomy and removal of the undescended right testis.

The definitive diagnosis was seminoma arising from retroperitoneal

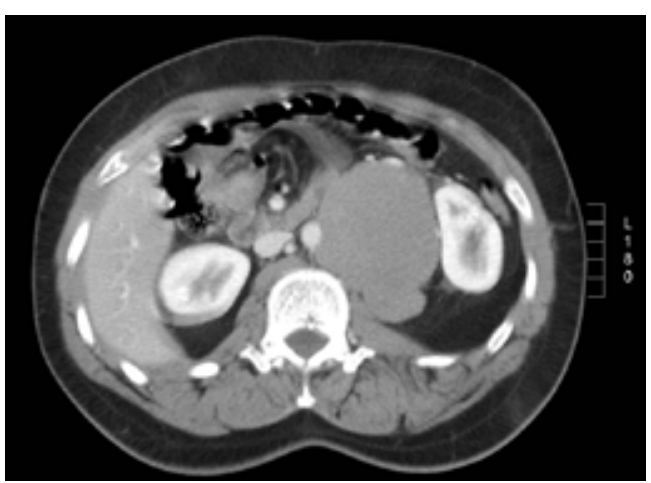

Figure 1: Abdominal CT scan showing a large retroperitoneal mass extending to left kidney.

*Corresponding author: Chiumento Costanza, Department of Radiation Oncology, IRCCS CROB, 1 Padre Pio Street, 85028 Rionero in Vulture, PZ, Italy, Tel: +39-328-3171087; Fax: +39-0972723509; E-mail: chiumento.costanza@gmail.com

Received March 28, 2013; Accepted April 20, 2013; Published April 23, 2013

Citation: Costanza C, Alba F, Alfredo T, Loredana L, Rocchina C, et al. (2013) A Case Report of Retroperitoneal Seminoma and Literature Review. J Nucl Med Radiat Ther 4: 148. doi:10.4172/2155-9619.1000148

Copyright: (c) 2013 Costanza C, et al. This is an open-access article distributed under the terms of the Creative Commons Attribution License, which permits unrestricted use, distribution, and reproduction in any medium, provided the original author and source are credited. 
Citation: Costanza C, Alba F, Alfredo T, Loredana L, Rocchina C, et al. (2013) A Case Report of Retroperitoneal Seminoma and Literature Review. J Nucl Med Radiat Ther 4: 148. doi:10.4172/2155-9619.1000148

Page 2 of 4

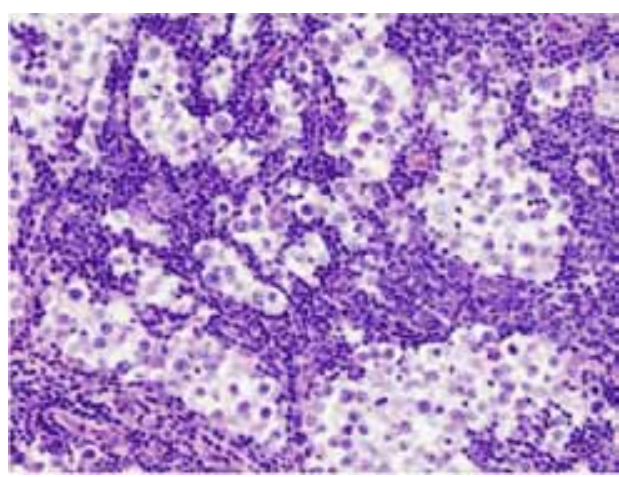

Figure 2: Classical seminoma revealed to a CT-guided biopsy of retroperitoneal mass.

space with atrophy of the right testis and without infiltration of left kidney and adrenal gland.

A CT scan performed after surgery showed a residual retroperitoneal mass of $2.6 \times 1.5 \mathrm{~cm}$ (Figure 3 ).

From September to November 2010 the patient received three cycles of cisplatin-based chemotherapy (PEB regimen: cisplatin 20 $\mathrm{mg} / \mathrm{m}^{2}$ on days $1-5$, etoposide $100 \mathrm{mg} / \mathrm{m}^{2}$ on days $1-5$, bleomycin $30 \mathrm{U}$ on days 2, 9, and 16, every 3 weeks). Patient completed chemotherapy otherwise he experienced acute haematological toxicity (neutropenia G3) that required the use of hematopoietic growth factors (G-CSF). A post-chemotherapy CT scan didn't show any residual mass.

From January to February 2011 the patient received radiotherapy. In particular, a 3D- Conformal Radiotherapy (3D-CRT), with nominal energy of $15 \mathrm{MV}$ was administered with a total dose of $25.2 \mathrm{~Gy}(1.8 \mathrm{~Gy} /$ day). Clinical target volume (CTV) was surgical bed plus para-aortic lymphonodes and ipsilateral pelvic nodes, Planned Target Volume (PTV) was CTV plus margins. During 3D-CRT acute gastrointestinal toxicity G2 (measured with RTOG Toxicity Scale) was recorded.

At last follow-up, on December 2012 a CT body scan revealed no recurrence disease in mediastinum and retroperitoneum space (Figure $4)$.

\section{Discussion}

Retroperitoneum represents the most likely site for secondary lesions, including metastatic lymphadenopathy from occult tumour, and primary tumours such as lymphoma, liposarcoma, teratoma etc. Retroperitoneal seminoma is a rare disease. Often it's difficult for clinicians distinguish primary germ cells tumour to metastatic lesion specially for seminoma, which tend to spread by lymphatic channel to retroperitoneal lymph nodes.

Previous reports in literature described a "burned out" phenomenon of germ cells tumours, consisting in extragonadal germ cell tumour with no evidence of neoplasm at the testis level [5-9].

The burned-out testicular tumour shows a distinctive constellation of findings that usually permits its recognition. A careful sonographic scrotal examination can reveal some abnormalities (echogenic foci, microlithiasis, scar formation and inhomogeneity) suggesting a regressed testicular tumour [10].

These ultrasonic features are nonspecific thus a ipsilateral inguinal orchiectomy is mandatory to confirm a disappeared testicle tumour throught a series of distinctive histological lesions (testicular atrophy, nodular scar etc. ) and to reduce probability of persistent testicular cancer [11]. More recently, Gurioli et al. [12] confirmed the important role of testicular ultrasonography in patients presenting CT of retroperitoneal mass, even if patients are completely asymptomatic and their physical examination appears normal.

In our case it was not possible to analyze hystologically the left testis because the patient refused left orchiectomy.

Treatment of EGCT requires a combination of therapies: surgery, cisplatin-based chemotherapy and radiotherapy $[6,13,14]$.

Seminomas tumours are very sensitive to chemotherapy and radiotherapy. Nichols [15] recommends primary abdominal radiotherapy for patients with small volume retroperitoneal seminomas (abdominal mass $<5 \mathrm{~cm}$ ) and chemotherapy for patients with larger volume disease The prognosis is excellent in cases of seminomatous histology with 5 -years survival rates $>90 \%$ achieved with platinumbased chemotherapy. Furthermore, cisplatin-based chemotherapy reduces the risk of metachronous contralateral testicular germ cell tumour (TGCT), witch cumulative incidence for patients with unilateral TGCT is $1-5 \%[16,17]$.

In our case due to the worsening of the clinical condition, the patient underwent debulking surgery followed by cisplatin-based chemotherapy and radiotherapy.

There are few cases reported in literature regarding patients with



Figure 3: A residual retroperitoneal mass, after two months of surgery.

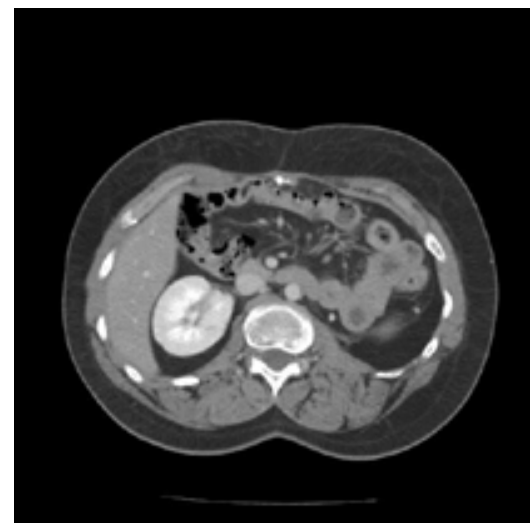

Figure 4: A CT scan at last follow-up showing no residual mass in retroperitoneal space. 
Citation: Costanza C, Alba F, Alfredo T, Loredana L, Rocchina C, et al. (2013) A Case Report of Retroperitoneal Seminoma and Literature Review. J Nucl Med Radiat Ther 4: 148. doi:10.4172/2155-9619.1000148

Page 3 of 4

\begin{tabular}{|c|c|c|c|c|c|c|c|c|}
\hline $\begin{array}{l}\text { Authors name (year of } \\
\text { publication) }\end{array}$ & $\mathrm{N}$ of pts & $\begin{array}{l}\text { Retroperitoneal } \\
\text { mass size }\end{array}$ & $\begin{array}{l}\text { Testicular } \\
\text { ultrasound } \\
\text { alterations }\end{array}$ & Tumour markers & $\begin{array}{c}\text { Ipsilateral } \\
\text { Orchiectomy }\end{array}$ & Types of treatment & Follow-up & Outcomes \\
\hline Abell (1965) [19] & 10 & NR & NR & NR & $3 / 10$ & RT alone ;S+RT & 29 months & NED \\
\hline Bookmayer (2001) [20] & 52 & $7 \mathrm{~cm}$ & NR & AFP normal, $\beta$ HCG, LDH high & NR & CHT; RT alone; CHT+RT & 49 months & 5-year OS $88 \%$ \\
\hline Tasu JP(2003) [21] & 2 & NR & Yes & NR & Yes & $\mathrm{S}+\mathrm{RT}$ & 72 months & NR \\
\hline Perimenis P (2005) [22] & 1 & $4 \mathrm{~cm}$ & Yes & Normal & Yes & S+ RT & 24 months & NED \\
\hline Kontos S (2009) [23] & 1 & $7 \mathrm{~cm}$ & Yes & Normal & Yes & $\mathrm{S}+\mathrm{CHT}$ & NR & NR \\
\hline Sachin Malde (2010)[24] & 1 & $12 \mathrm{~cm}$ & No & Normal & No & $\mathrm{CHT}$ & NR & NR \\
\hline Preda O. (2011)[25] & 1 & NR & Yes & AFP, $\beta$ HCG normal LDH high & Yes & $\mathrm{S}+\mathrm{CHT}$ & 5 months & NED \\
\hline
\end{tabular}

NR: Non reported; AFP: Alpha feto protein; $\beta$ HCG: Human chorionic gonadotropin beta: LDH: Lactate dehydrogenase; RT: Radiotheraphy: CHT: Chemiotherapy: S: Surgery: OS: Overall Survival: NED: Non evidence disease

Table1: A comparison of similar published case of retroperitoneal seminoma and outcomes.

retroperitoneal seminoma. These studies showed favourable outcomes both for short and long follow-up periods with combined modality treatment approach and revealing the higher frequency of metastatic retroperitoneal tumours from primary unevolved testicular tumour [5,18-23] (Table 1).

The association of germ cell tumours (GCTs) with gonadal dysgenesis is well known [24].

According to literature, our patient has been grouped within the "Testicular Dysgenesis Syndrome" only for the presence of right cryptorchidism. The histological examination of right testis revealed atrophy without signs of dysgenesis. It was not possible to investigate on the left testis because of patient refused biopsy or orchiectomy. The patient has a dysmorphic syndrome consisting in ptosis, diastasis of the abdomen rectum muscles, hip dysplasia and undescended right testis. A PCR analysis of FMR-1 (locus FRAXA) was detected in all family components. After a preliminary analysis was not identified yet a gene related to his dysmorphic syndrome and the genetic evaluation is still in progress.

One of the current areas of attention for pathologists and oncologists is the improvement of diagnostics for CIS (or intratubular germ cell neoplasia unclassified or testicular intraepithelial neoplasia) which occurred upon on third of patients with retroperitoneal and mediastinal GCTs [25-27].

Recent data have provided potential diagnostic tools including CIS detection in semen and novel stem cell markers for immunohistochemical diagnosis of gonadal and extragonadal GCTs, these methods may become applicable for screening or as an auxiliary test that allow a careful follow-up $[28,29]$.

\section{Conclusion}

GCTs are a very interesting tumors entity with specific biological and clinical characteristics. Although retroperitoneal seminoma is rare, this entity should be considered in the differential diagnosis of a male patient presenting with a mass in the retroperitoneum. Our case confirms the curability of retroperitoneal seminoma even in presence of bulky disease. However the increase knowledge about immunohistochemistry of GCTs and the research of novel histological markers, could adopted a new global perspective about investigation and treatment of these tumours.

\section{References}

1. Walsh PC, Retik AB, Darracott Vaughan E, Wein AJ (2002) Neoplasms of the tesits. (8thedn), Campbell's Urology, WB Saunders, London.

2. Mukherji SK, Rojiani AM, Younathan CM, Ros P (1994) CT findings of retroperitoneal malignant mesenchymoma. Abdom Imaging 19: 82-83.
3. McKenney JK, Heerema-McKenney A, Rouse RV (2007) Extragonadal germ cell tumors: a review with emphasis on pathologic features, clinical prognostic variables, and differential diagnostic considerations. Adv Anat Pathol 14: 69-92.

4. Schmoll HJ (2002) Extragonadal germ cell tumors. Ann Oncol 13 4: 265-272.

5. Perimenis P, Athanasopoulos A, Geraghty J, Macdonagh R (2005) Retroperitoneal seminoma with 'burned out' phenomenon in the testis. Int J Urol 12: 115-116.

6. Ojea Calvo A, Rodríguez Alonso A, Pérez García D, Domínguez Freire $F$ Alonso Rodrigo A, et al. (1999) Extragonadal germ cell tumor with "burned-out" phenomenon in the testis. Actas Urol Esp 23: 880-884.

7. Goss PE, Schwertfeger L, Blackstein ME, Iscoe NA, Ginsberg RJ, et al. (1994) Extragonadal germ cell tumors. A 14-year Toronto experience. Cancer 73 1971-1979.

8. Weber O, Hubert J, Grignon Y, Mangin P (1996) [Spontaneously involuting metastatic seminoma of the testis ("burned-out seminoma"). Report of a case presenting with supraclavicular adenopathy]. Prog Urol 6: 278-281.

9. Borrego Hernándo J, Guinda Sevillano C, Laguna Pes MP, Zazo A, Gimeno A, et al. (1998) [Retroperitoneal germinal tumor: extragonadal or burned out phenomenon of testicular primary? Presentation of a clinical case]. Actas Uro Esp 22: 170-174.

10. Tasu JP, Faye N, Eschwege P, Rocher L, Bléry M (2003) Imaging of burnedout testis tumor: five new cases and review of the literature. $\mathrm{J}$ Ultrasound Med 22: 515-521.

11. Böhle A, Studer UE, Sonntag RW, Scheidegger JR (1986) Primary or secondary extragonadal germ cell tumors? J Urol 135: 939-943.

12. Gurioli A, Oderda M, Vigna D, Peraldo F, Giona S, et al. (2013) [Two cases of retroperitoneal metastasis from a completely regressed burned-out testicular cancer.] Urologia 0: 0.

13. Sugiyama T, Hirano Y, Ushiyama T, Suzuki K, Fujita K, et al. (2000) [Burnedout testicular tumor: a case report]. Hinyokika Kiyo 46: 829-832.

14. Kebapci M, Can C, Isiksoy S, Aslan O, Oner U (2002) Burned-out tumor of the testis presenting as supraclavicular lymphadenopathy. Eur Radiol 12: 371-373.

15. Nichols CR (1998) Testicular cancer. Curr Probl Cancer 22: 187-274.

16. Fosså SD, Chen J, Schonfeld SJ, McGlynn KA, McMaster ML, et al. (2005) Risk of contralateral testicular cancer: a population-based study of 29,515 U.S. men. J Natl Cancer Inst 97: 1056-1066.

17. Andreassen KE, Grotmol T, Cvancarova MS, Johannesen TB, Fosså SD (2011) Risk of metachronous contralateral testicular germ cell tumors: a population-based study of 7,102 Norwegian patients (1953-2007). Int J Cancer 129: $2867-2874$

18. Abell MR, Fayos JV, Lampe I (1965) Retroperitoneal Germinomas (Seminomas) without evidence of testicular involvement. Cancer 18: 273-290.

19. Bokemeyer C, Droz JP, Horwich A, Gerl A, Fossa SD, et al. (2001) Extragonada seminoma: an international multicenter analysis of prognostic factors and long term treatment outcome. Cancer 91: 1394-1401.

20. Tasu JP, Faye N, Eschwege P, Rocher L, Bléry M (2003) Imaging of burnedout testis tumor: five new cases and review of the literature. $\mathrm{J}$ Ultrasound Med 22: $515-521$. 
Citation: Costanza C, Alba F, Alfredo T, Loredana L, Rocchina C, et al. (2013) A Case Report of Retroperitoneal Seminoma and Literature Review. J Nucl Med Radiat Ther 4: 148. doi:10.4172/2155-9619.1000148

Page 4 of 4

21. Kontos S, Doumanis G, Karagianni M, Politis V, Simaioforidis V, et al. (2009) Burned-out testicular tumor with retroperitoneal lymph node metastasis: a case report. J Med Case Rep 3: 8705.

22. Malde S (2010) Primary retroperitoneal seminoma: an unusual cause of testicular pain. JRSM Short Rep 1: 63.

23. Preda O, Nicolae A, Loghin A, Borda A, Nogales FF (2011) Retroperitoneal seminoma as a first manifestation of a partially regressed (burnt-out) testicular germ cell tumor. Rom J Morphol Embryol 52: 193-196.

24. Rutgers JL, Scully RE (1987) Pathology of the testis in intersex syndromes. Semin Diagn Pathol 4: 275-291.

25. Schmoll HJ, Souchon R, Krege S, Albers P, Beyer J, et al. (2004) European consensus on diagnosis and treatment of germ cell cancer: a report of the
European Germ Cell Cancer Consensus Group (EGCCCG). Ann Oncol 15: 1377-1399.

26. Skakkebaek NE (1972) Possible carcinoma-in-situ of the testis. Lancet 2: 516 517.

27. Daugaard G, Rørth M, von der Maase H, Skakkebaek NE (1992) Management of extragonadal germ-cell tumors and the significance of bilateral testicular biopsies. Ann Oncol 3: 283-289.

28. Fosså SD, Aass N, Heilo A, Daugaard G, E Skakkebaek N, et al. (2003) Testicular carcinoma in situ in patients with extragonadal germ-cell tumours: the clinical role of pretreatment biopsy. Ann Oncol 14: 1412-1418.

29. Hoei-Hansen CE (2008) Application of stem cell markers in search for neoplastic germ cells in dysgenetic gonads, extragonadal tumours, and in semen of infertile men. Cancer Treat Rev 34: 348-367. 